\title{
Suplementação com prebiótico, probiótico e simbiótico para juvenis de tambaqui a duas densidades de estocagem
}

\author{
Rafael Vieira de Azevedo(1), João Carlos Fosse Filho(1), Samuel Louzada Pereira(1), Leonardo Demier Cardoso(1), \\ Manuel Vazquez Vidal Júnior(1) e Dalcio Ricardo de Andrade ${ }^{(1)}$
}

\begin{abstract}
(1)Universidade Estadual do Norte Fluminense Darcy Ribeiro, Avenida Alberto Lamego, № 2.000, Horto, CEP $28015-620$ Campos dos Goytacazes, RJ, Brasil. E-mail: azevedorv84@gmail.com, joao.fosse@hotmail.com, samuell_lp@hotmail.com, leonardodemier@hotmail.com, mvidal@uenf.br, dalcio@uenf.br
\end{abstract}

Resumo - O objetivo deste trabalho foi avaliar o efeito da suplementação de rações, com prebiótico (mananoligossacarídeo), probiótico (Bacillus subtilis) e simbiótico, em juvenis de tambaqui (Colossoma macropomum), em duas densidades de estocagem, quanto aos parâmetros de crescimento, utilização do alimento, sobrevivência e econômicos. Um total de 192 juvenis $(2,4 \pm 0,2 \mathrm{~g})$ foi distribuído em 32 aquários $(20 \mathrm{~L})$, em delineamento inteiramente casualizado, em arranjo fatorial $2 \times 4$, com quatro repetições, durante oito semanas. Testaram-se 0,35 e 1,05 $\mathrm{kg} \mathrm{m}^{-3}$ para a densidade de estocagem. A suplementação constituiu-se de: $2 \mathrm{~g} \mathrm{~kg}^{-1}$ de prebiótico; $2 \mathrm{~g} \mathrm{~kg}^{-1}$ de probiótico; $2 \mathrm{~g} \mathrm{~kg}^{-1}$ de prebiótico $+2 \mathrm{~g} \mathrm{~kg}^{-1}$ de probiótico; e controle. A densidade de estocagem não influenciou a sobrevivência dos peixes, embora tenha causado a redução dos parâmetros econômicos e de crescimento. A suplementação com probiótico e simbiótico aumentou o crescimento, melhorou a utilização do alimento e os parâmetros econômicos. A ração controle apresentou o menor índice de eficiência econômica, enquanto o maior índice foi obtido pelas rações suplementadas com simbiótico. Os parâmetros de crescimento, utilização do alimento e econômicos aumentaram com a suplementação com probiótico e simbiótico, em rações para juvenis de tambaqui, embora não haja efeito sinergístico entre o prebiótico e o probiótico avaliados.

Termos para indexação: Bacillus subtilis, Colossoma macropomum, mananoligossacarídeo.

\section{Prebiotic, probiotic and synbiotic supplementation in diets for juvenile tambaquis at two stocking densities}

\begin{abstract}
The objective of this work was to evaluate the effect of prebiotic (mannan oligosaccharides), probiotic (Bacillus subtilis), and synbiotic diet supplementations on juvenile tambaquis (Colossoma macropomum), at two stocking densities, for growth, food utilization, survival, and economic parameters. A total of 192 juveniles $(2.4 \pm 0.2 \mathrm{~g})$ was distributed in 32 aquaria $(20 \mathrm{~L})$, in a completely randomized design, in a $2 \times 4$ factorial arrangement, with four replicates, during eight weeks. Tests were performed for 0.35 and $1.05 \mathrm{~kg} \mathrm{~m}^{-3}$ stocking density. The supplementation was constituted of: $2 \mathrm{~g} \mathrm{~kg}^{-1}$ prebiotic; $2 \mathrm{~g} \mathrm{~kg}^{-1}$ probiotic; $2 \mathrm{~g} \mathrm{~kg}^{-1}$ prebiotic $+2 \mathrm{~g} \mathrm{~kg}^{-1}$ probiotic; and a control. Stocking density had no effect on fish survival, although it decreased economic and growth parameters. Probiotic and synbiotic supplementation increased growth, and improved feed utilization and economic parameters. The control diet showed the lowest economic efficiency index, while the highest index was obtained by diets supplemented with synbiotic. Growth, food utilization, and economic parameters increased with the probiotic and synbiotic supplementation in diets for juvenile tambaquis, although there is no synergistic effect between the evaluated prebiotic and probiotic supplementations.
\end{abstract}

Index terms: Bacillus subtilis, Colossoma macropomum, mannan oligosaccharides.

\section{Introdução}

O tambaqui (Colossoma macropomum), originário da América do Sul, de ocorrência natural nas bacias dos rios Amazonas e Orinoco, é a segunda maior espécie de escama em água doce (Silva et al., 2007). Apresenta características favoráveis à produção intensiva, como fácil aquisição de juvenis, tolerância a baixas concentrações de oxigênio dissolvido e alto valor de mercado (Izel \& Melo, 2004; Silva et al., 2007). Em 2012, foi a principal espécie nativa cultivada no Brasil, com produção aquícola estimada em aproximadamente 99 mil toneladas (Instituto Brasileiro de Geografia e Estatística, 2013).

A expansão e intensificação da piscicultura, associada ao aumento de estratégias de produção 
cada vez mais intensivas, com maiores densidades de estocagem, tem resultado no aparecimento de doenças que causam consideráveis perdas econômicas e impedem o seu desenvolvimento sustentável (Gómez et al., 2007). Os antibióticos foram usados em larga escala como estratégias de prevenção e tratamento de doenças na piscicultura. No entanto, o desenvolvimento de bactérias resistentes, a presença de resíduos de antibióticos na carne e a destruição da população microbiana no ambiente aquático de cultivo (Marques et al., 2005) levaram à pesquisa por estratégias alternativas ao uso de antibióticos. Uma delas, que tem gerado grande interesse por parte de pesquisadores, é a introdução de imunoestimulantes em rações (Kiron, 2012).

Prebióticos são compostos não digeríveis por enzimas, sais e ácidos produzidos pelo organismo, mas seletivamente fermentados pelos microrganismos do trato gastrintestinal. Esses compostos estão presentes nos ingredientes da dieta ou são adicionados a ela por meio de fontes exógenas concentradas (Gibson \& Roberfroid, 1995). Probióticos são microrganismos vivos que, quando administrados em quantidades apropriadas, conferem benefício à saúde do hospedeiro, por melhorar o equilíbrio da microbiota no intestino (Verschuere et al., 2000). Os simbióticos são a mistura de prebióticos e probióticos que fornece o benefício de ambos, principalmente em razão dos efeitos sinergísticos (Gibson \& Roberfroid, 1995). Esta aplicação combinada baseia-se no princípio de que o prebionte proporciona ao probionte vantagem competitiva (fonte de energia para fermentação) sobre as populações endógenas, o que favorece sua sobrevivência e o seu estabelecimento no trato gastrintestinal do hospedeiro (Gibson \& Roberfroid, 1995).

Alguns estudos têm mostrado os efeitos benéficos dos prebióticos e dos probióticos para peixes, tais como a melhora na utilização do alimento, a modulação da microflora intestinal, o aumento da resposta imune e o antagonismo a patógenos, o que gera maior sobrevivência dos peixes (Verschuere et al., 2000; Ringo et al., 2010). Contudo, apesar do sucesso obtido pela suplementação isolada de prebióticos e probióticos, poucos estudos avaliaram sua suplementação em conjunto na piscicultura, em especial sobre os parâmetros econômicos.
O objetivo deste trabalho foi avaliar o efeito da suplementação de rações, com prebiótico (mananoligossacarídeo), probiótico (Bacillus subtilis) e simbiótico, em juvenis de tambaqui (Colossoma macropomum), em duas densidades de estocagem, quanto aos parâmetros de crescimento, utilização do alimento, sobrevivência e econômicos.

\section{Material e Métodos}

O estudo foi realizado no Setor de Bioensaios em Aquicultura Intensiva, do Laboratório de Zootecnia, Centro de Ciências e Tecnologias Agropecuárias, Universidade Estadual do Norte Fluminense Darcy Ribeiro (Uenf), em Campos dos Goytacazes, RJ.

O prebiótico utilizado foi o mananoligossacarídeo oriundo da parede celular da levedura Saccharomyces cerevisiae. Como microrganismos probióticos, utilizaram-se bactérias na forma de pó que continha esporos liofilizados de Bacillus subtilis - cada grama continha $1 \times 10^{10}$ unidades formadoras de colônias (UFC). O simbiótico foi formado pela mistura (1:1) do prebiótico e do probiótico.

Oito tratamentos foram avaliados, durante oito semanas, em um delineamento inteiramente casualizado, em arranjo fatorial $2 \times 4$ (densidade de estocagem x suplementação), com quatro repetições cada. O fator densidade de estocagem constituiu-se de $0,35 \mathrm{e} 1,05 \mathrm{~kg} \mathrm{~m}^{-3}$. O fator suplementação constituiu-se de controle (sem suplementação com prebiótico e probiótico); $2 \mathrm{~g} \mathrm{~kg}^{-1}$ de prebiótico; $2 \mathrm{~g} \mathrm{~kg}^{-1}$ de probiótico; $2 \mathrm{~g} \mathrm{~kg}^{-1}$ de prebiótico $+2 \mathrm{~g} \mathrm{~kg}^{-1}$ de probiótico.

Utilizaram-se 192 juvenis de tambaqui $(2,4 \pm 0,2 \mathrm{~g})$, adquiridos no setor de Aquicultura do Instituto Federal do Espírito Santo, Campus Alegre. Os peixes foram distribuídos aleatoriamente em 32 aquários experimentais de vidro $(0,45 \times 0,30 \times 0,19 \mathrm{~m})$, com volume útil individual de $20 \mathrm{~L}$, entrada e saída de água independentes, conectados a um sistema de recirculação de água com filtros mecânico, biológico e ultravioleta, além de controle de temperatura por aquecedor equipado com termostato.

As rações experimentais (Tabela 1) foram elaboradas com o auxílio do programa computacional Super Crac (TD Software, Viçosa, MG, Brasil).

Os alimentos foram moídos em moinho tipo faca, peneirados $(0,5 \mathrm{~mm})$ e misturados em misturador tipo "Y". Em seguida, o antioxidante, o premix 
mineral-vitamínico, o óleo de soja, o prebiótico e o probiótico foram adicionados e homogeneizados com os alimentos de acordo com a formulação de cada ração.

As rações foram peletizadas, tendo-se umedecido previamente a mistura com água aquecida. Após o processamento, os péletes foram secos em estufa $\left(45^{\circ} \mathrm{C}\right)$ de ventilação forçada por 24 horas. Após esse período, as rações foram analisadas bromatologicamente quanto aos teores de matéria seca, proteína bruta, fibra bruta, extrato etéreo, matéria mineral (Silva \& Queiroz, 2006), energia bruta com uso de bomba calorimétrica 1341 (Parr Instrument Company, IL, USA) e microbiologicamente, para averiguar a viabilidade do microrganismo (Bacillus subtilis). As rações com probiótico continham $1,71 \times 10^{7} \mathrm{UFC}^{-1}$

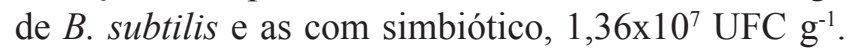
As rações controle e o prebiótico não continham o microrganismo. As rações foram identificadas e armazenadas em recipientes de plástico mantidos sob refrigeração até o início do experimento.

Tabela 1. Composição das rações experimentais com base na matéria natural.

\begin{tabular}{lcccc}
\hline Ingrediente $\left(\mathrm{g} \mathrm{kg}^{-1}\right)$ & Controle & Prebiótico & Probiótico & Simbiótico \\
\hline Farelo de soja & 410,0 & 410,0 & 410,0 & 410,0 \\
Farelo de trigo & 250,0 & 248,0 & 248,0 & 246,0 \\
Farelo de milho & 200,0 & 200,0 & 200,0 & 200,0 \\
Farinha de peixe & 79,7 & 79,7 & 79,7 & 79,7 \\
Amido de milho & 34,0 & 34,0 & 34,0 & 34,0 \\
Óleo de soja & 16,1 & 16,1 & 16,1 & 16,1 \\
Suplemento & 10,0 & 10,0 & 10,0 & 10,0 \\
Mananoligossacarídeo & - & 2,0 & - & 2,0 \\
Bacillus subtilis & - & - & 2,0 & 2,0 \\
Antioxidante BHT & 0,2 & 0,2 & 0,2 & 0,2 \\
\hline Composição proximal & & & & \\
$\quad$ Matéria seca $\left(\mathrm{g} \mathrm{kg}^{-1}\right)$ & 864,66 & 867,52 & 867,52 & 865,71 \\
Proteína bruta $\left(\mathrm{g} \mathrm{kg}^{-1}\right)$ & 276,64 & 276,61 & 272,32 & 275,58 \\
Energia bruta $\left(\mathrm{kcal} \mathrm{kg}^{-1}\right)$ & 4114 & 4106 & 4111 & 4098 \\
Fibra bruta $\left(\mathrm{g} \mathrm{kg}^{-1}\right)$ & 49,79 & 49,60 & 49,31 & 49,40 \\
Extrato etéreo $\left(\mathrm{g} \mathrm{kg}^{-1}\right)$ & 44,69 & 44,62 & 44,33 & 44,55 \\
Matéria mineral $\left(\mathrm{g} \mathrm{kg}^{-1}\right)$ & 127,72 & 138,28 & 143,43 & 152,38 \\
\hline
\end{tabular}

${ }^{(1)}$ Composição por kg do suplemento mineral-vitamínico: $\mathrm{Mg}, 2.600 \mathrm{mg}$; Zn, $14.000 \mathrm{mg}$; Fe, $10.000 \mathrm{mg}$; Cu, $1.400 \mathrm{mg}$; Co, $20 \mathrm{mg}$; I, $60 \mathrm{mg}$; Se, $60 \mathrm{mg}$; vitamina A, $1.000 .000 \mathrm{UI}$; vitamina D3, $400 \mathrm{UI}$; vitamina $\mathrm{E}$, $10.000 \mathrm{mg}$; vitamina $\mathrm{K} 3,500 \mathrm{mg}$; vitamina B1, $2.500 \mathrm{mg}$; vitamina B2, $2.500 \mathrm{mg}$; vitamina B6, $2.500 \mathrm{mg}$; vitamina B12, $3.000 \mu \mathrm{g}$; vitamina C, $35.000 \mathrm{mg}$; ácido fólico, $500 \mathrm{mg}$; ácido pantotênico, $5.000 \mathrm{mg}$; niacina, $10.000 \mathrm{mg}$; biotina, $80.000 \mu \mathrm{g}$; colina, $200.000 \mathrm{mg}$; metionina, $130 \mathrm{~g}$; inositol, $5.000 \mathrm{mg}$; etoxiquin, $15.000 \mathrm{mg}$.
Os peixes foram alimentados ad libitum quatro vezes ao dia, às 8:00, 11:00, 14:00 e 17:00 h. Trinta minutos após cada alimentação, as sobras de rações eram sifonadas, congeladas e, após o término do experimento, secas em estufa e pesadas para correção do consumo de ração.

No início do experimento, todos os peixes foram pesados com uso de uma balança com precisão de $0,1 \mathrm{~g}$, modelo BD-150 (Instrutherm, SP, Brasil) e, após oito semanas, todos os peixes sobreviventes foram pesados. As rações, para cada repetição, foram pesadas com precisão de $0,1 \mathrm{~g}$, no início e ao final do experimento. A mortalidade dos animais foi registrada diariamente.

A temperatura e o oxigênio dissolvido (YSI 550A, YSI Corporation, MA, USA) e o pH (mPA 210, MS TECNOPON, Piracicaba, SP) foram mensurados diariamente, enquanto a amônia (HI83203, Hanna Instruments Inc., R I, USA) foi mensurada semanalmente, tendo-se obtido, durante o período experimental, os seguintes valores médios: $27,3 \pm 1,1^{\circ} \mathrm{C}$, temperatura; $5,11 \pm 0,95 \mathrm{mg} \mathrm{L}^{-1}$, oxigênio dissolvido; $6,67 \pm 0,21, \mathrm{pH} ;$ e $0,07 \pm 0,01 \mathrm{mg} \mathrm{L}^{-1}$, de amônia total.

A partir dos dados obtidos, foram determinados o consumo total de ração $(\mathrm{kg})$, a biomassa final $\left(\mathrm{kg} \mathrm{m}^{-3}\right)$, o ganho relativo em biomassa [(biomassa final / biomassa inicial) x 100], a conversão alimentar aparente (consumo total de ração / ganho em biomassa) e a taxa de sobrevivência [(indivíduos vivos / número inicial de indivíduos) x 100], como avaliação do desempenho zootécnico.

Para avaliar a viabilidade econômica da utilização das rações experimentais, foram coletados dados sobre o preço junto aos fornecedores dos ingredientes. $\mathrm{O}$ custo das rações foi calculado com base nos preços de varejo, no entanto, estes valores foram convertidos em dólar (R\$ 3,18, taxa de câmbio do dia 01 de junho de 2015). Os custos do quilograma das rações controle, prebiótico, probiótico e simbiótico foram, respectivamente, US\$ 0,352 , US\$ 0,357 , US\$ 0,362 e US\$ 0,367. Considerou-se US\$2,362 como o preço de venda do quilograma de peixe.

O custo médio da ração por quilograma em ganho de peso vivo foi calculado segundo Bellaver et al. (1985). A estimativa do custo total de produção, com uso apenas dos parâmetros custo com a alimentação e desempenho animal, foi obtida segundo Matsunaga et al. (1976). A receita bruta e o lucro operacional foram obtidos segundo Martin et al. (1998). Para avaliar o impacto 
financeiro dos tratamentos em relação à suplementação ou não de prebiótico, probiótico e simbiótico, foi calculado o índice de eficiência econômica conforme Barbosa et al. (1992).

Os dados obtidos foram submetidos à análise de variância e, quando houve diferenças significativas a $5 \%$ de probabilidade, aplicou-se o teste de Tukey, com uso do pacote estatístico SAS 9.1 (SAS Institute, Cary, NC, EUA). Os dados expressos em percentagem foram transformados de acordo com a fórmula $\mathrm{y}=\operatorname{arcoseno}(\mathrm{x})^{0,5}$.

\section{Resultados e Discussão}

Entre a densidade de estocagem e a suplementação com prebiótico, probiótico e simbiótico não se observou efeito da interação sobre o crescimento, a utilização do alimento, a sobrevivência e os parâmetros econômicos (Tabelas 2 e 3).

Não foi observada influência significativa da densidade de estocagem sobre a sobrevivência, tendose obtido média de $98,61 \%$. Resultados semelhantes foram obtidos por Brandão et al. (2004) e Gomes et al. (2006), com tambaqui, e Azevedo et al. (2015), com tilápia-do-nilo, espécies estudadas a diferentes

Tabela 2. Crescimento, utilização do alimento e sobrevivência de juvenis de tambaqui, conforme a densidade de estocagem e a suplementação com prebiótico, probiótico ou simbiótico ${ }^{(1)}$.

\begin{tabular}{|c|c|c|c|c|c|c|}
\hline Tratamento & $\begin{array}{c}\mathrm{BI} \\
\left(\mathrm{kg} \mathrm{m}^{-3}\right)\end{array}$ & $\begin{array}{c}\mathrm{BF} \\
\left(\mathrm{kg} \mathrm{m}^{-3}\right)\end{array}$ & $\begin{array}{c}\text { GRB } \\
(\%)\end{array}$ & $\begin{array}{c}\text { CTR } \\
\left(\mathrm{kg} \mathrm{m}^{-3}\right)\end{array}$ & $\begin{array}{r}\text { CAA } \\
\left(\mathrm{g} \mathrm{g}^{-1}\right)\end{array}$ & $\begin{array}{c}\text { SOB } \\
(\%)\end{array}$ \\
\hline \multicolumn{7}{|l|}{ Densidade } \\
\hline $0,35 \mathrm{~kg} \mathrm{~m}^{-3}$ & $0,35 \mathrm{~b}$ & $2,09 b$ & $551,98 \mathrm{a}$ & $2,12 b$ & $1,26 \mathrm{a}$ & $100,00 \mathrm{a}$ \\
\hline $1,05 \mathrm{~kg} \mathrm{~m}^{-3}$ & $1,01 \mathrm{a}$ & $4,30 \mathrm{a}$ & $427,49 \mathrm{~b}$ & $6,18 \mathrm{a}$ & $1,97 \mathrm{~b}$ & $97,22 \mathrm{a}$ \\
\hline \multicolumn{7}{|l|}{ Suplemento } \\
\hline Controle & $0,70 \mathrm{a}$ & $2,78 b$ & $429,24 b$ & $4,09 \mathrm{a}$ & $1,88 \mathrm{~b}$ & $97,22 \mathrm{a}$ \\
\hline Prebiótico & $0,69 a$ & $3,03 \mathrm{ab}$ & $459,05 \mathrm{ab}$ & $4,05 \mathrm{a}$ & $1,68 \mathrm{ab}$ & $98,61 \mathrm{a}$ \\
\hline Probiótico & $0,69 \mathrm{a}$ & $3,52 \mathrm{a}$ & $543,23 a$ & $4,34 \mathrm{a}$ & $1,47 \mathrm{a}$ & $100,00 \mathrm{a}$ \\
\hline Simbiótico & $0,69 \mathrm{a}$ & $3,46 a$ & $527,43 a$ & $4,13 \mathrm{a}$ & $1,42 \mathrm{a}$ & $98,61 \mathrm{a}$ \\
\hline \multirow[t]{2}{*}{ CV (\%) } & 3,35 & 15,56 & 12,84 & 5,93 & 17,10 & 4,88 \\
\hline & \multicolumn{6}{|c|}{ Valor de $\mathrm{p}$} \\
\hline Densidade (D) & 0,0001 & 0,0001 & 0,0001 & 0,0001 & 0,0001 & 0,1155 \\
\hline Suplemento (S) & 0,8773 & 0,0193 & 0,0034 & 0,1081 & 0,0101 & 0,7234 \\
\hline $\mathrm{D} \times \mathrm{S}$ & 0,8773 & 0,4604 & 0,7670 & 0,9939 & 0,2967 & 0,7234 \\
\hline
\end{tabular}

densidades de estocagem. O canibalismo e a queda da qualidade da água, geralmente, são apontados como responsáveis pela mortalidade em decorrência do aumento da densidade de estocagem (El-Sayed, 2002), fatores estes que não foram observados no presente estudo.

A maior densidade de estocagem resultou em maior biomassa final e consumo total de ração, em razão tanto do maior número de indivíduos quanto da baixa mortalidade (Tabela 2). Brandão et al. (2004) observaram maior aumento de produtividade de juvenis de tambaqui a densidades mais altas $(400 \mathrm{e}$ 500 peixes $\left.\mathrm{m}^{-3}\right)$ do que a densidades mais baixas (200 e 300 peixes $\mathrm{m}^{-3}$ ).

A densidade de estocagem influenciou o ganho relativo em biomassa e a conversão alimentar aparente (Tabela 2). A biomassa final, à maior densidade de estocagem, foi cerca de $105 \%$ mais alta que à menor densidade. Apesar disso, o ganho relativo em biomassa foi, em média, $29,12 \%$ superior nos peixes submetidos à menor densidade, o que indica que quanto maior a densidade de estocagem, menor o desempenho médio dos peixes. Alguns autores mostraram haver relação inversa entre aumento da densidade de estocagem e o crescimento e a utilização do alimento em peixes (El-Sayed, 2002; Brandão et al., 2004; Azevedo et al.,

Tabela 3. Avaliação econômica do uso de rações para juvenis de tambaqui, conforme a densidade de estocagem e a suplementação com prebiótico, probiótico ou simbiótico ${ }^{(1)}$.

\begin{tabular}{lccccc}
\hline Tratamento & $\begin{array}{c}\mathrm{CMR} \\
\left(\mathrm{US} \$ \mathrm{~m}^{-3}\right)\end{array}$ & $\begin{array}{c}\mathrm{CTA} \\
\left(\mathrm{US} \$ \mathrm{~m}^{-3}\right)\end{array}$ & $\begin{array}{c}\mathrm{CTP} \\
\left(\mathrm{US} \$ \mathrm{~kg}^{-1}\right)\end{array}$ & $\begin{array}{c}\mathrm{RB} \\
\left(\mathrm{US} \$ \mathrm{~m}^{-3}\right)\end{array}$ & $\begin{array}{c}\mathrm{LO} \\
\left(\mathrm{US} \$ \mathrm{~m}^{-3}\right)\end{array}$ \\
\hline Densidade \\
$0,35 \mathrm{~kg} \mathrm{~m}^{-3}$ & $0,45 \mathrm{~b}$ & $0,76 \mathrm{~b}$ & $0,37 \mathrm{~b}$ & $4,93 \mathrm{~b}$ & $4,31 \mathrm{~b}$ \\
$1,05 \mathrm{~kg} \mathrm{~m}^{-3}$ & $0,70 \mathrm{a}$ & $2,22 \mathrm{a}$ & $0,53 \mathrm{a}$ & $10,16 \mathrm{a}$ & $8,97 \mathrm{a}$ \\
\hline Suplemento & & & & \\
$\quad$ Controle & $0,66 \mathrm{~b}$ & $1,44 \mathrm{~b}$ & $0,49 \mathrm{a}$ & $6,56 \mathrm{~b}$ & $5,83 \mathrm{~b}$ \\
$\quad$ Prebiótico & $0,60 \mathrm{ab}$ & $1,45 \mathrm{~b}$ & $0,46 \mathrm{a}$ & $7,15 \mathrm{ab}$ & $6,31 \mathrm{ab}$ \\
$\quad$ Probiótico & $0,53 \mathrm{ab}$ & $1,57 \mathrm{a}$ & $0,43 \mathrm{a}$ & $8,30 \mathrm{a}$ & $7,28 \mathrm{a}$ \\
$\quad$ Simbiótico & $0,52 \mathrm{a}$ & $1,51 \mathrm{ab}$ & $0,42 \mathrm{a}$ & $8,16 \mathrm{a}$ & $7,14 \mathrm{a}$ \\
\hline CV (\%) & 17,01 & 5,92 & 12,21 & 15,56 & 15,02 \\
\hline \multicolumn{5}{c}{ Valor de $\mathrm{p}$} \\
Densidade (D) & 0,0001 & 0,0001 & 0,0001 & 0,0001 & 0,0001 \\
Suplemento (S) & 0,0297 & 0,0200 & 0,0526 & 0,0193 & 0,0230 \\
D x S & 0,3441 & 0,8220 & 0,4281 & 0,4604 & 0,4749 \\
\hline
\end{tabular}

${ }^{(1)}$ Médias seguidas por letras iguais, nas colunas, não diferem pelo teste de Tukey, a 5\% de probabilidade. CMR, custo médio da ração por quilograma, em ganho de peso vivo; CTA, custo total com alimentação; CTP, custo total de produção; RB, receita bruta; LO, lucro operacional. 
2015). Esses resultados podem ser explicados pelo maior requerimento de energia decorrente de interação comportamental antagônica, competição por alimento, mudanças na síntese de hormônios, enzimas e fatores de crescimento, além do aumento de estresse (Barton \& Iwama, 1991). Assim, a energia consumida na dieta pode ter sido mobilizada para as alterações fisiológicas decorrentes do estresse, o que explica a piora do crescimento e da conversão alimentar aparente.

Não houve influência significativa da suplementação com prebiótico, probiótico e simbiótico sobre o consumo total de ração e a taxa de sobrevivência (Tabela 2), o que corrobora os resultados obtidos por Azevedo et al. (2015) em estudo sobre tilápia-do-nilo. A semelhança dos valores de consumo total de ração é uma indicação de que a suplementação com prebiótico, probiótico e simbiótico não alterou a palatabilidade da ração, diferentemente dos resultados obtidos por Sado et al. (2008) em pesquisa sobre tilápia-do-nilo, em que a suplementação com mananoligossacarídeo provocou a redução do consumo de ração.

Quanto à taxa de sobrevivência, resultados semelhantes foram obtidos por Essa et al. (2010), com rações suplementadas com $B$. subtilis, e Azevedo et al. (2015), com rações suplementadas com mananoligossacarídeo em conjunto com B. subtilis. No presente estudo, mesmo que os peixes tenham sido submetidos a um fator estressante (densidade de estocagem), os efeitos da suplementação com prebiótico, probiótico e simbiótico, quanto ao parâmetro sobrevivência, podem ter sido mascarados em razão das demais condições experimentais (nutrição e manejo), que favoreceram a obtenção de taxas elevadas de sobrevivência (acima de 97\%).

A suplementação com prebiótico separadamente, em rações para juvenis de tambaqui, não melhorou os parâmetros de crescimento e a utilização do alimento, em comparação aos peixes submetidos ao tratamento controle (Tabela 2). Alguns estudos relataram a falta de efeito da suplementação com prebiótico para peixes (Sado et al., 2008; Buentello et al., 2010), enquanto outros estudos relatam a melhoria do crescimento e da utilização do alimento (Staykov et al., 2007; Azevedo et al., 2015). As diferenças de resultados podem ser explicadas por diferenças estruturais dos prebióticos utilizados, nível e tempo de suplementação, condições de cultivo, além da espécie e tamanho do peixe.
A suplementação com probiótico e simbiótico, em rações para tambaqui, aumentou a biomassa final, o ganho relativo de biomassa e melhorou significativamente a conversão alimentar aparente, em comparação aos resultados obtidos pelos animais submetidos à ração controle (Tabela 2).

Os efeitos da suplementação com probiótico sobre o crescimento e a utilização do alimento, bem como o efeito positivo da suplementação com Bacillus sp., têm sido estudados em grande número de espécies de peixes cultivados (Essa et al., 2010; Gupta et al., 2014). Os mecanismos pelos quais os probióticos podem melhorar o desempenho ainda não estão claros. Contudo, Bacillus sp. pode sintetizar algumas vitaminas ( $\mathrm{K}$ e $\mathrm{B}_{12}$ ), segundo Martens et al. (2002), e enzimas extracelulares (protease e amilase) segundo Azokpota et al. (2006), que podem melhorar o aproveitamento do alimento e aumentar o crescimento do hospedeiro.

Poucos estudos avaliaram a suplementação com simbiótico para peixes, e a suplementação conjunta de mananoligossacarídeo e Bacillus sp. na aquicultura resultou em melhoria do crescimento e utilização do alimento (Daniels et al., 2010; Azevedo et al., 2015). Segundo Cerezuela et al. (2011), um simbiótico é a combinação de prebiótico e probiótico de modo que ocorra sinergismo entre ambos, aumentando seus efeitos benéficos isolados, o que não foi observado no presente estudo.

Quanto à avaliação econômica, a densidade de estocagem influenciou o custo médio da ração por quilograma em ganho de peso vivo, o custo total com alimentação, o custo total de produção, a receita bruta e o lucro operacional (Tabela 3). Em média, o custo com ração para produzir um quilograma de peixe foi $55,56 \%$ maior, à maior densidade de estocagem, do que à menor densidade (Tabela 3); resultado semelhante foi obtido por Azevedo et al. (2015). De igual modo, o custo da alimentação foi, em média, $192,11 \%$ mais alto na maior densidade de estocagem. No entanto, mesmo com os custos de produção mais altos, a receita bruta $(106,09 \%)$ e o lucro operacional $(108,12 \%)$ foram maiores à densidade de estocagem maior do que na menor, o que pode ser relacionado à alta taxa de sobrevivência, obtida com os tratamentos à maior densidade de estocagem. Gomes et al. (2006) observaram melhoria do desempenho econômico (maiores receita bruta e lucro) de juvenis de tambaqui 
criados a densidades maiores (50 peixes $\mathrm{m}^{-3}$ ) em comparação às menores $\left(20,30 \mathrm{e} 40\right.$ peixes $\left.\mathrm{m}^{-3}\right)$.

Maior densidade de estocagem geralmente proporciona maior produtividade, porém, o crescimento individual e o aproveitamento do alimento tendem a ser menores. No entanto, o aumento da produtividade obtido no presente estudo com o aumento na densidade de estocagem pode compensar os melhores resultados obtidos para crescimento individual e conversão alimentar aparente, apresentados pelos peixes à menor densidade.

Em média, foram gastos $26,92 \%$ a mais para produzir um quilograma de peixe vivo, na alimentação de tambaquis com a ração controle, em comparação ao gasto com esse peixe alimentado com ração suplementada com simbiótico (Tabela 3). Resultados semelhantes foram obtidos por Dias et al. (2012), com a suplementação com probiótico para matrinxã (Brycon amazonicus), e Azevedo et al. (2015), com a suplementação com prebiótico, probiótico e simbiótico para tilápia-do-nilo.

A suplementação com prebiótico, probiótico e simbiótico não alterou o custo total de produção, enquanto a suplementação com probiótico aumentou o custo total com alimentação relativamente à suplementação com prebiótico e à ração controle (Tabela 3). No entanto, os maiores valores para receita bruta e lucro operacional foram obtidos em peixes alimentados com rações suplementadas com probiótico e simbiótico.

$\mathrm{O}$ aumento da densidade de estocagem provocou redução de cerca de $6,30 \%$ no índice de eficiência econômica (Figura 1). O menor índice de eficiência econômica $(80,47 \%)$, entre todos os tratamentos, foi obtido com a ração controle, enquanto o maior índice (100\%) foi obtido com a ração suplementada com simbiótico.

Segundo Guimarães et al. (2008), os custos com alimentação em piscicultura intensiva podem representar até $70 \%$ dos custos totais de produção. No presente trabalho, os maiores índices de eficiência econômica e desempenho zootécnico obtidos são indicativos da viabilidade econômica da inclusão de probiótico e simbiótico em rações para suplementação de juvenis de tambaqui. Deve-se, no entanto, observar os custos e a disponibilidade de cada um desses suplementos, ao utilizá-los como componentes em rações para essa espécie.

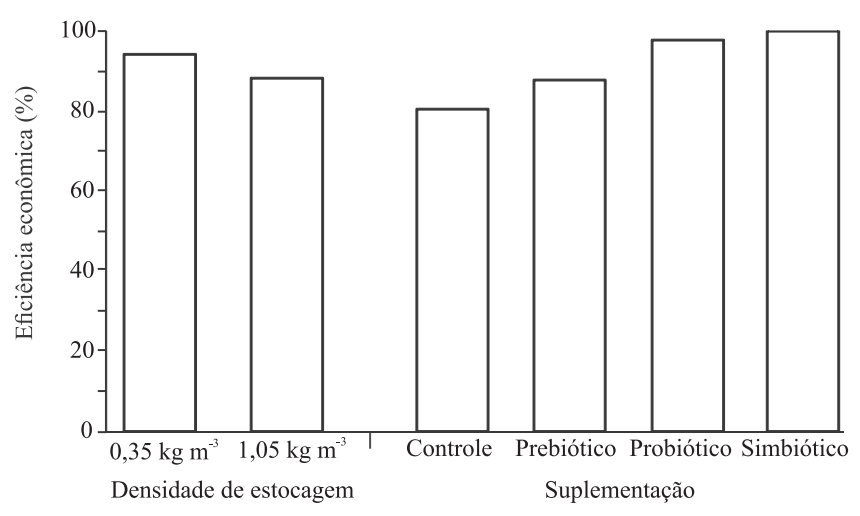

Figura 1. Índice de eficiência econômica de rações, para juvenis de tambaqui, com a densidade de estocagem e a suplementação de prebiótico, probiótico ou simbiótico.

\section{Conclusões}

1. O aumento da densidade de estocagem reduz o crescimento e a utilização do alimento, não afeta a sobrevivência de juvenis de tambaqui e aumenta os custos de produção, a receita bruta e o lucro operacional.

2. A suplementação com prebiótico, separadamente, não aumenta o crescimento, a utilização do alimento, a sobrevivência e os parâmetros econômicos de juvenis de tambaqui.

3. A suplementação de probiótico e simbiótico em rações para tambaqui melhora os parâmetros de crescimento e utilização de alimento e aumenta a receita bruta e o lucro operacional.

4. Não há efeito sinergístico entre o Bacillus subtilis e o mananoligossacarídeo, quando utilizados como suplementos em rações para juvenis de tambaqui.

\section{Agradecimentos}

À Fundação de Amparo à Pesquisa do Estado do Rio de Janeiro (Faperj, processo E-26/110.717/2013), pelo apoio financeiro; à Universidade Estadual do Norte Fluminense Darcy Ribeiro, pela concessão de bolsa.

\section{Referências}

AZEVEDO, R.V. de; FOSSE-FILHO, J.C.; CARDOSO, L.D.; MATTOS, D.C.; VIDAL-JÚNIOR, M.V.; ANDRADE, D.R. de. Economic evaluation of prebiotics, probiotics and symbiotics in juvenile Nile tilapia. Revista Ciência Agronômica, v.46, p.72-79, 2015. DOI: $10.1590 / \mathrm{S} 1806-66902015000100009$. 
AZOKPOTA, P.; HOUNHOUIGAN, D.J.; NAGO, M.C.; JAKOBSEN, M. Esterase and protease activities of Bacillus spp. from afitin, iru and sonru; three African locust bean (Parkia biglobosa) condiments from Benin. African Journal of Biotechnology, v.5, p.265-272, 2006.

BARBOSA, H.P.; FIALHO, E.T.; FERREIRA, A.S.; LIMA, G.J.M.M. de; GOMES, M. F.M. Triguilho para suínos nas fases inicial de crescimento, crescimento e terminação. Revista Brasileira de Zootecnia, v.21, p.827-837, 1992.

BARTON, B.A.; IWAMA, G.K. Physiological changes in fish from stress in aquaculture with emphasis on the response and effects of corticosteroids. Annual Review of Fish Diseases, v.1, p.3-26, 1991. DOI: 10.1016/0959-8030(91)90019-G.

BELLAVER, C.; FIALHO, E.T.; PROTAS, J.F. da S.; GOMES, P.C. Radícula de malte na alimentação de suínos em crescimento e terminação. Pesquisa Agropecuária Brasileira, v.20, p.969-974, 1985.

BRANDÃO, F.R.; GOMES, L. de C.; CHAGAS, E.C.; ARAÚJO, L.D. de. Densidade de estocagem de juvenis de tambaqui durante a recria em tanques-rede. Pesquisa Agropecuária Brasileira, v.39, p.357-362, 2004. DOI: 10.1590/ S0100-204X2004000400009.

BUENTELLO, J.A.; NEILL, W.H.; GATLIN, D.M. Effects of dietary probiotics on the growth, feed efficiency and non-specific immunity of juvenile red drum Sciaenops ocellatus fed soybean-based diets. Aquaculture Research, v.41, p.411-418, 2010. DOI: $10.1111 /$ j.1365-2109.2009.02178.x.

CEREZUELA, R.; MESEGUER, J.; ESTEBAN, M.A. Current knowledge in synbiotic use for fish aquaculture: a review. Journal of Aquaculture Research \& Development, S1, p.1-7, 2011. DOI: 10.4172/2155-9546.S1-008.

DANIELS, C.L.; MERRIFIELD, D.L.; BOOTHROYD, D.C.; DAVIES, S.J.; FACTOR, J.R.; ARNOLD, K.E. Effect of dietary Bacillus spp. and mannan oligosaccharides (MOS) on European lobster (Homarus gammarus L.) larvae growth performance, gut morphology and gut microbiota. Aquaculture, v.304, p.49-57, 2010. DOI: 10.1016/j.aquaculture.2010.03.018.

DIAS, D. de C.; FURLANETO, F. de P.B.; AYROZA, L.M. da S.; TACHIBANA, L.; ROMAGOZA, E.; RANZANI-PAIVA, M.J.T. Probiotic in feeding of juvenile matrinxã (Brycon amazonicus): economic viability. Acta Scientiarum. Animal Sciences, v.34, p.239-243, 2012. DOI: 10.4025/actascianimsci.v34i3.13257.

EL-SAYED, A.-F.M. Effects of stocking density and feeding levels on growth and feed efficiency of Nile tilapia (Oreochromis niloticus L.) fry. Aquaculture Research, v.33, p.621-626, 2002. DOI: $10.1046 /$ j.1365-2109.2002.00700.x.

ESSA, M.A.; EL-seRAFY, S.S.; EL-EZABI, M.M.; DABOOR, S.M.; ESMAEL, N.A.; LALL, S.P. Effect of different dietary probiotics on growth, feed utilization and digestive enzymes activities of Nile tilapia, Oreochromis niloticus. Journal of the Arabian Aquaculture Society, v.5, p.143-161, 2010.

GIBSON, G.R.; ROBERFROID, M.B. Dietary modulation of the human colonic microbiota: introducing the concept of prebiotics. Journal of Nutrition, v.125, p.1401-1412, 1995.
GOMES, L. de C.; CHAGAS, E.C.; MARTINS-JÚNIOR, H.; ROUBACH, R.; ONO, E.A.; LOURENÇO, J.N. de P. Cage culture of tambaqui (Colossoma macropomum) in a central Amazon floodplain lake. Aquaculture, v.253, p.374-384, 2006. DOI: 10.1016/j.aquaculture.2005.08.020.

GÓMEZ, R.G.D.; BALCÁZAR, J.L.; SHEN, M.A. Probiotic as control agents in aquaculture. Journal of Ocean University of China, v.6, p.76-79, 2007. DOI: 10.1007/s11802-007-0076-8.

GUIMARÃES, I.G.; MIRANDA, E.C. de; RIBEIRO, V.L.; MARTINS, G.P.; MIRANDA, C.C. de. Farinha de camarão em dietas para tilápia do Nilo (Oreochromis niloticus). Revista Brasileira de Saúde e Produção Animal, v.9, p.140-149, 2008.

GUPTA, A.; GUPTA, P.; DHAWAN, A. Dietary supplementation of probiotics affects growth, immune response and disease resistance of Cyprinus carpio fry. Fish \& Shellfish Immunology, v.41, p.113-119, 2014. DOI: 10.1016/j.fsi.2014.08.023.

INSTITUTO BRASILEIRO DE GEOGRAFIA E ESTATÍSTICA. Produção da Pecuária Municipal 2013. Rio de Janeiro: IBGE, 2013. v.41, 108p.

IZEL, A.C.U.; MELO, L.A.S. Criação de tambaqui (Colossoma macropomum) em tanques escavados no estado do Amazonas. Manaus: Embrapa Amazônia Ocidental, 2004. 20p. (Embrapa Amazônia Ocidental. Documentos, 32).

KIRON, V. Fish immune system and its nutritional modulation for preventive health care. Animal Feed Science and Technology, v.173, p.111-133, 2012. DOI: 10.1016/j.anifeedsci.2011.12.015.

MARQUES, A.; DINH, T.; IOAKEIMIDIS, C.; HUYS, G.; SWINGS, J.; VERSTRAETE, W.; DHONT, J.; SORGELOOS, P.; BOSSIER, P. Effects of bacteria on Artemia franciscana cultured in different gnotobiotic environments. Applied and Environmental Microbiology, v.71, p.4307-4317, 2005. DOI: 10.1128/AEM.71.8.4307-4317.2005.

MARTENS, J.-H.; BARG, H.; WARREN, M.J.; JAHN, D. Microbial production of vitamin B-12. Applied Microbiology and Biotechnology, v.58, p.275-285, 2002. DOI: 10.1007/ s00253-001-0902-7.

MARTIN, N.B.; SERRA, R.; OLIVEIRA, M.D.M.; ÂNGELO, J.A.; OKAWA, H. Sistema integrado de custos agropecuários CUSTAGRI. Informações Econômicas, v.1, p.7-28, 1998.

MATSUNAGA, M.; BEMELMANS, P.F.; TOLEDO, P.E.N. de; DULLEY, R.D.; OKAWA, H.; PEDROSO, I.A. Metodologia do custo de produção adotado pelo IEA. Agricultura em São Paulo, v.1, p.123-139, 1976.

RINGO, E.; OLSEN, R.E.; GIFSTAD, T.O.; DALMO, R.A.; AMLUND, H.; HEMRE, G.-I.; BAKKE, A.M. Prebiotics in aquaculture: a review. Aquaculture Nutrition, v.16, p.117-136, 2010. DOI: $10.1111 /$ j.1365-2095.2009.00731.x.

SADO, R.Y.; BICUDO, A.J. de A.; CYRINO, J.E.P. Feeding dietary mannan oligosaccharides to juvenile Nile tilapia, Oreochromis niloticus, has no effect on hematological parameters and showed decreased feed consumption. Journal of the World Aquaculture Society, v.39, p.821-826, 2008. DOI: 10.1111/j.1749-7345.2008. 00219.x.

Pesq. agropec. bras., Brasília, v.51, n.1, p.9-16, jan. 2016 DOI: $10.1590 / \mathrm{S} 0100-204 \mathrm{X} 2016000100002$ 
SILVA, A.M.D. da; GOMES, L. de C.; ROUBACH, R. Growth, yield, water and effluent quality in ponds with different management during tambaqui juvenile production. Pesquisa Agropecuária Brasileira, v.42, p.733-740, 2007. DOI: 10.1590/ S0100-204X2007000500017.

SILVA, D.J.; QUEIROZ, A.C. Análise de alimentos: métodos químicos e biológicos. 3.ed. Viçosa: Ed. da UFV, 2006. 235p.

STAYKOV, Y.; SPRING, P.; DENEV, S.; SWEETMAN, J. Effect of a mannan oligosaccharide on the growth performance and immune status of rainbow trout (Oncorhynchus mykiss). Aquaculture International, v.15, p.153-161, 2007. DOI: 10.1007/ s10499-007-9096-z.

VERSCHUERE, L.; ROMBAUT, G.; SORGELOOS, P.; VERSTRAETE, W. Probiotic bacteria as biological control agents in aquaculture. Microbiology and Molecular Biology Review, v.64, p.655-671, 2000. DOI: 10.1128/ MMBR.64.4.655-671.2000.

Recebido em 2 de junho de 2015 e aprovado em 16 de outubro de 2015 